\title{
MARXISMO, SUJEITO E SUBJETIVIDADE. NEGRI DIANTE DO ANTI- HUMANISMO ALTHUSSERIANO
}

\author{
MARXISM, SUBJECT AND SUBJECTIVITY. NEGRI IN THE FACE OF THE ANTI-HUMANISM OF \\ ALTHUSSER
}

Émerson Pirola*

\begin{abstract}
RESUMO
Um debate de longa data no interior do marxismo é o entre perspectivas que tenderiam para uma leitura da obra marxiana centrada nas análises sobre a constituição de sujeitos políticos de e em luta, na constituição de uma classe social revolucionária que enfrente a exploração capitalista, e perspectivas centradas nas transformações do capitalismo ou nas dinâmicas estruturais da economia. Podemos dizer, esquematicamente, que as primeiras perspectivas são "subjetivistas" e as segundas "objetivistas". Nos anos 1960 esse debate se viu determinado pela chamada polêmica do anti-humanismo, lançada por Louis Althusser contra o marxismo por ele criticado como humanista, visto que advogaria por uma noção de Sujeito idealista e abstrata, descolada dos processos estruturais da economia política capitalista. Antonio Negri, por sua vez, deu e dá grande importância para a noção de subjetividade na análise crítica e enfrentamento do capitalismo. Negri, entretanto, não ignora as críticas efetuadas por Althusser ao chamado humanismo, tomando-as como pré-requisito para o desenvolvimento original de sua teoria. Mostramos, portanto, como Althusser desenvolve suas críticas do Sujeito e do humanismo para então desenvolver as posições de Negri diante destas, a construção de sua própria teoria da subjetividade, resgatada do Marx dos Grundrisse, e apontar as limitações do pensamento althusseriano no que concerne à subjetividade.
\end{abstract}

PALAVRAS-CHAVE: Sujeito. Anti-humanismo. Subjetividade. Negri. Althusser.

\section{ABSTRACT}

A long-standing debate within Marxism is the one between perspectives that would tend towards a reading of the Marxian work centered on analyzes of the constitution of political subjects in and in class struggle, the constitution of a revolutionary social class facing capitalist exploitation, and perspectives centered on the transformations of capitalism or the structural dynamics of the economy in general. We can say, schematically, that the first perspective are "subjectivist" and the second one "objectivist". In the 1960s this debate was determined by Louis Althusser's so-called polemic of anti-humanism, in which he criticized certain Marxism as an humanism, since it would advocate for an idealist and abstract notion of subject detached from the structural processes of capitalist political economy. Antonio Negri, in turn, gave and gives great importance to the notion of subjectivity in the dynamics and confrontation of capitalism. Negri, however, does not ignore the criticisms made by Althusser of the humanism, taking them as a prerequisite for the original development of his theory. We thus show how Althusser develops his criticisms of the Subject and humanism to develop Negri's positions for and against them, the construction of his own theory of subjectivity, rescued from Marx's Grundrisse, and we point out the limitations of Althusser's thought as regards subjectivity.

KEYWORDS: Subject. Antihumanism. Subjeticvity. Negri. Althusser.

\footnotetext{
* Mestre, com bolsa CNPq, em Filosofia pela PUCRS. Doutorando em Filosofia pela PUCRS, com bolsa CAPES. E-mail: emerson.pirola@acad.pucrs.br.
} 


\section{INTRODUÇÃO}

O marxismo enquanto campo teórico é marcado pela controvérsia entre pensadores que, de um lado, reivindicam a obra de Marx para afirmar uma filosofia política e a constituição de um sujeito de luta e, de outro, reivindicam o legado marxiano para efetuar análises estruturais dos movimentos da economia. De maneira geral, podemos dizer que a primeira posição caracteriza uma perspectiva subjetivista da filosofia marxista, enquanto a segunda caracteriza uma perspectiva objetivista - de um lado o foco nos sujeitos de luta ou revolucionários e na sua constituição, de outro uma análise calculista e determinista dos movimentos do capital através das transformações do campo econômico. Esse debate, que historicamente se apresentou em diferentes modos e períodos, sofreu nas décadas de 1960 e 1970 uma determinação famosa através da polêmica do "anti-humanismo teórico", efetuada por Louis Althusser, na França, no qual o autor defendia uma posição estruturalista e objetivista contra as perspectivas que reivindicavam uma centralidade das noções de Sujeito para a teoria marxista. A crítica efetuada por Althusser abalou o pensamento marxista e mobilizou uma série de respostas fervorosas (como é o caso da crítica de E. P. Thompson intitulada A miséria da teoria (1981)). Entretanto, pretendemos analisar como um filósofo específico se portou diante da controvérsia anti-humanista iniciada por Althusser: o italiano Antonio Negri, egresso da tradição teórica e militante do operaísmo e da Autonomia Operária, que reivindicava e reivindica a centralidade da subjetividade para um bom entendimento do capitalismo, aproxima-se da perspectiva althusseriana em alguns pontos, mas diverge em outros, como veremos. O estudo das divergências entre Negri e Althusser pode jogar luz sobre os méritos e as limitações tanto das perspectivas humanistas quanto das estruturalistas, além de impedir que a obra de Negri possa ser lida como de um "subjetivismo idealista" como os objetos da crítica do francês.

Nossa investigação começa pelos desafios deixados pela crítica do Sujeito, próprios do anti-humanismo althusseriano e do estruturalismo francês. Levar em consideração essas críticas constitui pré-requisito para a apresentação seguinte da investigação, sobre a atualização do método de pesquisa resgatado de Marx efetuada por Antonio Negri. Como coloca Timothy Murphy (2011), os motivos e os problemas enfrentados por Negri em seu trabalho teórico, nos diferentes campos em que atua - político, histórico, ontológico, ético são próximos dos desenvolvidos pelo (pós-)estruturalismo. Começamos com as críticas efetuadas ao marxismo humanista e à noção de Sujeito acompanhando, sobretudo o anti- 
humanismo de Louis Althusser e a sua tese do corte epistemológico na obra marxiana. Através das teses da história como um processo sem sujeito e das elucubrações de Althusser sobre o aspecto necessariamente ideológico da constituição do sujeito, passamos aos desenvolvimentos, historicamente simultâneos, das noções de composição de classe e subjetividade próprias do operaísmo italiano. Antonio Negri toma como ponto de partida a crítica da metafísica do Sujeito efetuada por Althusser e pelos estruturalistas, mas afirma a necessidade de uma pesquisa materialista sobre as produções de subjetividades. As teses de Étienne Balibar (2003), sobre a inseparabilidade dos chamados estruturalismo e pósestruturalismo nos é bastante importante nessa passagem, visto que pretendemos seguir a aproximação, efetuada por Timothy Murphy (2011), entre a filosofia de Negri com as problemáticas do estruturalismo e do pós-estruturalismo.

Na sequência apresentamos a apropriação efetuada por Negri do método de pesquisa desenvolvido por Marx para a análise e a crítica do modo de produção capitalista. Em 1978, a convite de Althusser, Negri ministra na École Normale Supérieure um curso que resultará em seu livro Marx além de Marx (2016). O que Negri afirma a partir do texto marxiano é a necessidade não só de uma reaplicação da metodologia marxiana nos tempos contemporâneos, mas a necessidade de uma atualização do próprio método.

\section{ANTI-HUMANISMO E CRÍTICA DO SUJEITO}

Louis Althusser se tornou famoso no mundo intelectual nos anos 60 com o lançamento das duas principais obras de sua primeira fase ${ }^{1}$ em 1965: Por Marx, coletânea de artigos escritos e publicados individualmente entre 60 e 64; e Ler o Capital, livro coletivo com a participação do próprio e de seus alunos Étienne Balibar, Roger Establet, Pierre Macherey e Jaques Rancière. A fama e o alcance que essas obras conseguiram, porém, deu-se de forma polêmica. Polêmica causada, sobretudo, pelo objetivo central do filósofo francês: propor uma leitura da obra de Marx desvinculada do humanismo que imperava nos meios marxistas à época. Essa polêmica passa simultaneamente por um desenvolvimento de uma

\footnotetext{
${ }^{1}$ Luiz Eduardo Motta (2014) separa a trajetória de Althusser em quatro momentos distintos: a primeira sendo a do lançamento da polêmica anti-humanista, na década de 60; após há uma fase de autocrítica e retificação, sobretudo na primeira metade de 1970; segue-se uma radicalização da segunda fase e da tomada de posições políticas leninistas; e, por fim, há a derradeira fase do materialismo aleatório ou materialismo do encontro, na qual o autor intenta a construção de uma filosofia para o marxismo através de teorias do encontro e abandona a terminologia do materialismo dialético.
} 
teoria da ciência e da ideologia, através da introdução da noção de corte epistemológico, resgatada de Gaston Bachelard, e da aplicação dos mesmos desenvolvimentos à obra de Marx. Dessa forma, um estudo marxológico é efetuado para marcar oposição em relação aos marxismos do Sujeito, tanto em sua forma hegeliana (Lukács) quanto humanista (Sartre, E. P. Thompson, Erich Fromm ${ }^{2}$ ), visto que, segundo Althusser, as diferentes escolas marxistas nascem devido a diferentes (e problemáticas) leituras da obra marxiana. Através do corte epistemológico, portanto, Althusser divide a obra de Marx entre um período ideológico e humanista e um período propriamente científico e marxista ${ }^{3}$.

É importante lembrar que após a repressão da Revolução Húngara por parte do poder soviético e após o XX congresso do Partido Comunista da União Soviética (PCUS), onde o "discurso secreto de Khrushchov" revelou os "crimes do stalinismo", ambos os acontecimentos de 1956, o movimento comunista internacional bem como o marxismo enquanto escola filosófica entraram em certa crise. Inicia-se, então, tanto nos próprios países socialistas quanto nos partidos de viés marxista mundo afora, um processo de desestalinização. Os humanistas tomavam suas posições como o caminho natural na busca de uma alternativa ao stalinismo, o que fica claro no seguinte trecho de E. P. Thompson (1981, p. 208), proponente do socialismo humanista inglês e um dos críticos de Althusser: "Há duas tradições, cuja bifurcação e afastamento foram lentos e cuja declaração final de antagonismo irreconciliável foi retardada - como fato histórico - até 1956". O trabalho inicial de Althusser é marcado por esse contexto, e é aí que se encontra um de seus maiores méritos: como indica Luiz Eduardo Motta (2014, p. 41), essas obras estão ligadas à

uma inventividade teórica que rompe ao mesmo tempo com a ortodoxia predominante nos aparelhos partidários de esquerda (stalinistas) e com o ecumenismo inspirado na palavra de ordem do humanismo como via única à desestalinização iniciada a partir do XX Congresso do PCUS.

Na perspectiva althusseriana, o humanismo, ainda que com boas razões para se opor ao stalinismo, acabava por abandonar algo de fundamental à perspectiva marxiana:

\footnotetext{
${ }^{2}$ É curioso como a própria "querela sobre o humanismo", a polêmica iniciada por Althusser, origina de um texto que fora encomendado por Erich Fromm, que estava, em 1963, organizando uma coletânea sobre marxismo e humanismo. O texto de Althusser, de tom contrário ao buscado por Fromm para a coletânea, fora rejeitado (ALTHUSSER, 1999, p. 9-11).

${ }^{3}$ Não estamos interessados diretamente no acerto ou no erro das leituras efetuadas da obra de Marx pela parte de Althusser ou dos autores humanistas (ou ainda, adiante, da parte de Negri). Não pretendemos um estudo de marxologia. Apresentamos brevemente a marxologia althusseriana, pois ela ajuda a esclarecer suas posições sobre o Sujeito e o seu anti-humanismo.
} 
Aqueles que imputam a Stalin, além de seus crimes e seus erros, o conjunto de nossas decepções, de nossos erros e de nossos infortúnios, em qualquer domínio, correm o risco de vir a ficar muito desconcertados ao constatarem que o fim do dogmatismo filosófico não nos devolveu a filosofia marxista em sua integridade (ALTHUSSER, 2015, p. 21).

Os desenvolvimentos de Althusser têm, pois, o objetivo de defender o marxismo diante dos reducionismos stalinistas e das formas humanistas de marxismo que pretendiam tomar seu lugar.

Para propor suas teses anti-humanistas, Althusser recorrerá à Epistemologia e à História da Ciência francesas para introduzir na obra de Marx um corte epistemológico, conceito tomado da obra de Gaston Bachelard, a fim de cindir a trajetória intelectual de Marx entre um período humanista e um período propriamente marxista. Para os fins que nos interessam, é importante salientar que o corte em questão marca, entre o humanismo ideológico da Crítica da filosofia do direito de Hegel [1843] (MARX, 2010a) e, sobretudo, dos Manuscritos econômico-filosóficos [1844] (MARX, 2010b), de um lado, e A ideologia alemã [1845] (MARX; ENGELS, 2007), por outro, uma ruptura epistemológica radical. Segundo Althusser, a problemática própria do marxismo e, logo, sua constituição enquanto ciência, aconteceria em 1845, em A ideologia alemã. A fundação de uma problemática científica própria é o que separa a ciência recém-fundada da ideologia precedente. Como coloca Rocha (1976, p. 306),

uma problemática ocasiona a emergência dum saber científico, ou mesmo a refundação do saber dentro dum mesmo sistema teórico [...] A prática científica elabora problemas na área duma estrutura teórica definida - a sua problemática -, que constitui a condição de possibilidade e a determinação absoluta das formas de situação de qualquer problema, num determinado momento da ciência.

Dessa forma Althusser introduz no campo do marxismo a distinção entre o "Jovem Marx" e o "Marx maduro". Qual seria, porém, o fundamento dessa distinção? O que marca o corte? Como veremos, o corte passa pelas noções centrais de Homem e de Sujeito, próprias do Marx dos Manuscritos e dos marxismos humanista e hegeliano; não por acaso, visto que estes marxismos tomam nas obras do Jovem Marx suas principais fontes filosóficas, inclusive quando leem as obras da maturidade, como $O$ capital [1867], visto que as leem na chave humanista das primeiras obras ${ }^{4}$.

\footnotetext{
4““Toda a teoria, em voga, da 'reificação' [de Lukács] repousa sobre a projeção da teoria da alienação dos textos da juventude, e particularmente dos Manuscritos de 1844, sobre a teoria do 'fetichismo' d'O Capital" (ALTHUSSER, 2015, p. 202, n. 7).
} 
Segundo Motta (2014, p. 22),

a interpretação humanista do materialismo histórico afirma que a história é a produção do homem pelo homem, e a essência do homem é o trabalho; assim sendo, o conceito do trabalho é o conceito base do materialismo histórico, e a história é a história da alienação do trabalho humano.

Essa perspectiva está fundamentalmente ligada a uma noção ideológica de "homem", uma noção abstrata, geral, que não pensa as particularidades históricas, a materialidade da vida social humana em sua radicalidade e multideterminação. Ou, quando pensa, pensa através de um "historicismo do sujeito", que continua a respeitar a eternidade e a autoidentidade dos dois polos, de Sujeito e Objeto (ALTHUSSER, 1999, p. 36-37) ${ }^{5}$. O Sujeito é pensado enquanto uma interioridade trans-histórica que lida com as diferentes determinações históricas externas. Numa concepção desse tipo, o Sujeito, identificado como o Homem, acaba por ter uma relação excepcional com a história, acaba por ser a Origem e o Fim do processo histórico, processo que é resultado de sua produção. Ou, em uma formulação simples, o Homem é o sujeito da História. Contra isso, Althusser afirma que a "história é um imenso sistema 'natural-humano’ em movimento, cujo motor é a luta de classes. A história é um processo; e um processo sem sujeito. A questão de saber como 'o homem faz a história' desaparece completamente" (1978, p. 28, grifos do autor).

Como o marxista estruturalista comenta, “só Deus 'faz' a matéria com a qual 'faz' o mundo" (ALTHUSSER, 1978, p. 22) - o sujeito da história só pode o ser se for transcendente/transcendental em relação ao resto, ao não sujeito, ao "objeto", ao mundo histórico que ele mesmo produz. Em tal linha de pensamento, o homem é um "pequeno deus laico" (p. 22).

Deparamo-nos com a célebre tese da "história como um processo sem Sujeito". É perceptível, porém, a sua motivação: abandonar uma noção idealista, transcendente ou transcendental, de Sujeito-Homem que invadia o marxismo através da filosofia moderna (o cogito nas suas mais diferentes formas). Antes de pensar esse Sujeito essencial em sua interioridade, mesmo que historicizado ou constituído intersubjetivamente (como na

\footnotetext{
${ }^{5}$ É interessante como o estatuto de "historicismo do sujeito" é imputado, por Althusser, à A ideologia alemã (juntamente das Teses contra Feuerbach), obra que constitui o marco do corte, mas que, por uma confusa mistura de dialética hegeliana e humanismo feuerbachiano (ALTHUSSER, 1999, p. 37-9), não contém ainda o grau de desenvolvimento científico que estará presente em $O$ capital.
} 
fenomenologia $\left.{ }^{6}\right)^{7}$, é necessário pensar as diferentes formas materiais de organização social e econômica, os diferentes modos de produção em suas contingências históricas.

\begin{abstract}
'O homem' é um mito da ideologia burguesa: o M. L. [Marxismo-Leninismo] não pode partir do 'homem'. Ele 'parte do período social economicamente dado': e, no final de sua análise, pode 'chegar' aos homens reais. Esses homens são então o ponto de chegada de uma análise que parte das relações sociais do modo de produção existente, das relações de classe e de luta de classe. Esses homens são homens inteiramente diferentes do 'homem' da ideologia burguesa. (ALTHUSSER, 1978, p. 30, grifos do autor).
\end{abstract}

Portanto, Althusser não rejeita por completo uma noção de "homem", mas abandona as suas concepções humanistas, a insistência em alguma forma de essência identificável que seria como que uma causa transitiva do movimento da história. Não se pode compreender a história reduzindo-a a "uma Origem, uma Essência ou uma Causa (ainda que fosse o Homem), que seria o Sujeito - o Sujeito, esse 'ser' ou 'essência' posto como identificável, ou seja, como existente sob a forma da unidade de uma interioridade" (ALTHUSSER, 1978, p. 69, grifos do autor). Concepções desse modo constituem o que chamamos, acompanhando Negri (2003, p. 180), de “metafísica do Sujeito". Entretanto, é válido salientar, do mesmo modo que Althusser rejeita uma noção de Homem humanista, própria da ideologia burguesa herdeira do idealismo cartesiano, sem abandonar por completo a noção de homem, o mesmo acontece com a categoria de sujeito: "Eu sustento que 'os homens concretos' (no plural) são necessariamente sujeitos $n a$ história, visto que atuam na história enquanto sujeitos. Mas não há Sujeito (singular) da história” (ALTHUSSER, 1988, p. 86, grifos do autor). Ainda assim, avançando ao próximo ponto da teorização de Althusser sobre o sujeito e a ideologia, veremos como é limitada, até mesmo bloqueada, a capacidade dada pelo autor aos "sujeitos na história".

Além de suas críticas ao humanismo teórico marxista, presentes sobretudo em Por Marx (2015), na Resposta a John Lewis (em [1978]), e na publicação póstuma A querela do humanismo (1999; 2002), Althusser desenvolve em Aparelhos ideológicos de estado (1983), seu texto mais conhecido e lido (MONTAG, 2010, p. 59-60), uma construção própria da noção de sujeito, em outros termos do que nos textos de polêmica anti-humanista. Nesse trabalho, Althusser intenta um desenvolvimento original do conceito de ideologia, conceito

\footnotetext{
6“'Althusser, talvez surpreendentemente, não tomou os partidários da intersubjetividade como aliados objetivos; pelo contrário, ele viu essa teoria como, talvez, a mais sofisticada variante da filosofia do sujeito, uma defesa disfarçada como uma crítica" (MONTAG, 2010, p. 56).

${ }^{7}$ São nossas todas as traduções de citações cujo original é em língua estrangeira.
} 
recorrente na tradição marxista, que é indissociável, para ele, da noção de sujeito. Para o autor, a reprodução das condições de produção capitalistas passa simultaneamente por dois tipos de aparelhos: 1) o Aparelho Repressivo de Estado (ARE) - “o governo, a administração, o exército, a polícia, os tribunais, as prisões, etc.” (1983, p. 67); 2) Os Aparelhos Ideológicos de Estado (AIE). O primeiro funciona, no limite, através do uso da violência em diversas formas. Os AIE, por outro lado, constituem-se nas diferentes instituições sociais, como a escola, a família, as igrejas, o sindicato etc. e funcionam através da ideologia. O que diferencia os dois modos de aparelho é que enquanto o ARE funciona principalmente através da repressão e da violência, os AIE funcionam principalmente através da ideologia (segundo o autor, não existem aparelhos “puros”) (1983, p. 68-70). Para a reprodução das relações de produção, para fazer manter a sociedade com seus poderes estabelecidos e hierarquias, os AIE acabam sendo, de longe, mais importantes que o ARE. Como coloca Paul Ricoeur (1994, p. 52) a propósito do texto de Althusser, "o poder nu nunca funciona; no uso do poder político uma mediação ideológica é inescapavelmente envolvida".

Qual o modo de funcionamento dos AIE na reprodução das relações de produção existentes? E qual sua relação com o sujeito? Falando formalmente, visto que as diferentes ideologias funcionam através da mesma estrutura formal (ALTHUSSER, 1983, p. 99): a ideologia, materialmente funcionando nos diferentes Aparelhos Ideológicos de Estado, "recruta" os indivíduos concretos como sujeitos através de um processo de interpelação. A ideologia é o que transforma um indivíduo em um sujeito. O sujeito, dessa forma, existe enquanto sujeito na e pela ideologia, que, da mesma forma, existe apenas no e pelo sujeito. Aí Althusser introduz outra noção: a de Sujeito, com maiúscula, para diferenciar os múltiplos sujeitos produzidos pela interpelação ideológica do Sujeito, unitário e absoluto, próprio da ideologia (da ideologia em questão: Deus, na religião; o Homem, no Humanismo). Retomamos: a ideologia interpela indivíduos (concretos) em sujeitos (ideológicos) através do Sujeito. A ideologia existe em função do sujeito e o sujeito existe apenas através do Sujeito da ideologia. Através dos AIE a ideologia interpela os indivíduos enquanto sujeitos ideológicos (formulação tautológica, como coloca Althusser). Porém, como Althusser salienta, é um erro pensar que há um antes e um depois da interpelação: o indivíduo é sempre já sujeito. A interpelação sempre já ocorreu: “a ideologia interpela os indivíduos enquanto sujeitos. [...] a ideologia sempre/já interpelou os indivíduos como sujeitos, o que quer dizer que os indivíduos foram sempre/já interpelados pela ideologia como sujeitos" (ALTHUSSER, 1983, p. 98). Não há, indivíduo ou sujeito, fora da ideologia. Isso se deve, como salientam Montag 
(2010) e Ricoeur (1994), à filiação direta do conceito de ideologia com o conceito de inconsciente advindo da psicanálise. Althusser (1983, p. 85, grifo do autor) afirma enfaticamente que a ideologia não tem história:

\begin{abstract}
Se eterno significa, não a transcendência a toda história (temporal), mas omnipresença, transhistória e portanto imutabilidade em sua forma em toda extensão da história, eu retomarei palavra por palavra da expressão de Freud e direi: $a$ ideologia é eterna, como o inconsciente. E acrescentarei que esta aproximação me parece teoricamente justificada pelo fato de que a eternidade do inconsciente não deixa de ter relação com a eternidade da ideologia em geral.
\end{abstract}

Dessa forma, podemos concluir que a ideologia, em seu funcionamento especular entre sujeitos e Sujeito, está sempre presente na vida dos sujeitos. Na definição de Althusser (1983, p. 85), “a ideologia representa a relação imaginária dos indivíduos com suas condições de existência", condição que é eterna e própria das sociedades humanas ${ }^{8}$. Isso, somado ao fato de que "os sujeitos são sujeito em um duplo sentido: eles são sujeitos no sentido de agentes, autores de pensamento e ação, mas também seres sujeitados [subjected beings] que são declarados livres em ordem de voluntariamente se sujeitar ao Sujeito" (MONTAG, 2010, p. 57), nos dá a inevitável conclusão de que qualquer mudança radical nas relações de produção não pode passar pelos sujeitos, visto que só há sujeito da ideologia e esta existe apenas através dos aparelhos ideológicos que servem, justamente, para reproduzir as relações de produção.

Tiramos duas grandes conclusões dos desenvolvimentos do trabalho de Althusser que expusemos: a rejeição da tese do Homem enquanto Sujeito da história; uma concepção do sujeito indissociável da ideologia e da reprodução. A crítica das noções humanistas e idealistas de um Homem-Sujeito trans-histórico coloca, por consequência, a abertura da pesquisa marxista para a radicalidade histórica dos contextos economicamente dados e para surgimento de um "homem" concreto e determinado pela materialidade dos diferentes modos de produção dentro da contingência do sistema "natural-humano", que é a história. O corte epistemológico, simultaneamente demarcando a separação da ideologia humanista do Jovem Marx e da ciência da história própria do Marx d'O capital e entre o marxismo anti-humanista althusseriano e o marxismo humanista de boa parte dos filósofos marxistas de seu contexto, supera o Sujeito e o Homem na direção dos modos de produção e da luta de classes. Por outro lado, a concepção de ideologia como sempiterna e como o mecanismo por excelência da

\footnotetext{
"'Somente uma concepção ideológica do mundo pôde imaginar sociedades sem ideologias e admitir a ideia utópica de um mundo onde a ideologia (e não alguma de suas formas históricas) desapareceria sem deixar vestígios, para ser substituída pela ciência." (ALTHUSSER, 2015, p. 192, grifo do autor).
} 
interpelação dos sujeitos pelo Sujeito e da reprodução das relações de produção proíbe que se tenha nos sujeitos um caminho possível para a luta política. Dessa forma, não é estranho notar que a ciência marxista, o materialismo histórico, tenha a palavra final sobre os caminhos da luta política - visto que a ciência, toda ciência, é constituída em um corte epistemológico em relação à ideologia, e só há sujeitos na e pela ideologia, há uma rejeição mútua entre sujeito e ciência. Não há sujeito da ciência, posto que o sujeito é uma noção ideológica ${ }^{9}$. Como nos chama a atenção Ricoeur, tal concepção de corte epistemológico e de ciência enquanto negação total da ideologia, do sujeito, “às vezes tem severas implicações políticas. Ante a invasão da Tchecoslováquia, em 1968, por exemplo, Althusser se manteve em silêncio; sua posição o autorizou a argumentar que, de um ponto de vista puramente teórico, o movimento de reforma estava errado" (RICOEUR, 1994, p. 49). Pode-se fazer uma leitura similar de algumas posições de Althusser sobre as revoltas do Maio de 68 (2017).

Althusser efetua uma dura crítica da metafísica do Sujeito própria do marxismo humanista, tanto em sua versão dialético-hegeliana quanto em sua versão fenomenológico existencial, crítica acompanhada por Negri. Abre assim, como ele mesmo coloca, a pesquisa para a constituição histórica e determinada dos "homens concretos" e dos "sujeitos na história". Entretanto, Althusser acaba por proibir de antemão, com uma teoria da ideologia implacável e totalizante, a pesquisa sobre as possibilidades emancipatórias da mesma subjetividade, aberta e histórica, que ele ajudou a abrir espaço. A sua redução "a cinzas [d]o mito filosófico (teórico) do homem" (ALTHUSSER, 2015, p. 190) acaba por levar junto toda possibilidade revolucionária que parta das subjetividades em luta e hipostasia o marxismo em uma ciência da luta de classes para além dos próprios sujeitos em luta. Disso para uma teoria de vanguarda revolucionária o passo é curto, como é indício a sempre polêmica relação de Althusser com o Partido Comunista Francês: sempre crítico, mas sempre dentro; sempre crítico, mas nunca o rejeitando - envolvimento com o PCF que Negri implicitamente se opusera (MURPHY, 2011, p. 103). A seguir, vemos como Negri, partindo do contexto do operaísmo italiano, se aproxima e se distancia do anti-humanismo althusseriano.

\footnotetext{
${ }^{9}$ A respeito das diferentes propostas sobre a relação entre ciência, ideologia e sujeito no contexto do estruturalismo, envolvendo Althusser, Lacan, e um séquito comum e em transição entre ambos, ver, principalmente, Hallward, (2012); mas também Maniglier (2010).
} 


\section{CLASSE E SUBJETIVIDADE}

Antonio Negri possui grande proximidade com o contexto da filosofia francesa dos anos 60 e 70, com o (pós-)estruturalismo em particular ${ }^{10}$. Acompanhamos, desse modo, o que coloca Murphy (2011) sobre a similaridade das problemáticas entre Negri e o movimento (pós-)estruturalista. O próprio Negri (2005, p. 161) explicita sua proximidade: "eu acredito que a influência que o marxismo italiano exerceu em Foucault (e em Deleuze) foi extremamente importante. Era uma relação simbiótica, no final das contas; há algo profundamente unitário sobre toda essa experiência na Itália e na França". Em outro texto, justamente Da produção de subjetividade, Negri (2003a, p. 183) diz que a reforma do marxismo efetuada pelo operaísmo italiano "leva às mesmas conclusões do percurso foucaultiano". Negri afirma, por fim, que fora necessário "lavar a roupa no Sena" (2007, p. 14): "Tratava-se de confrontar o operaísmo italiano e o pensamento pós-estruturalista francês, forçando um curto-circuito entre Foucault e Deleuze, de um lado, e as lutas operárias que se desenrolaram na Itália e ao pensamento que elas produziram, do outro" (NEGRI, 2007, p. 14).

Das obras que lhe servem de principais influências filosóficas encontra-se a de dois (pós-)estruturalistas: Gilles Deleuze e Michel Foucault. Deleuze, inclusive, prefaciou sua principal monografia sobre Spinoza, A anomalia selvagem (NEGRI, 1993). Além disso, quando exilado político na França, Negri encontrou em Félix Guattari um grande amigo (NEGRI, 2006, p. 61) e colaborador intelectual, tendo produzido em conjunto, em 1985, o livro intitulado Les nouveaux espaces de liberté, publicado no Brasil como As verdades nômades (GUATTARI; NEGRI, 2017). Há ainda, nessa herança estruturalista de Negri, dois acontecimentos não tão conhecidos ou declarados, mas que não deixam de refletir preocupações comuns: (1) em 1956 Negri ganha uma bolsa de estudos para fazer sua tese de doutorado na École Normale Supérieure (ENS). Sua tese, dedicada à pesquisa sobre o jovem Hegel, é orientada por Jean Hyppolite, autor que efetuava, poderíamos dizer, uma leitura "préestruturalista" da obra hegeliana e faz com que Negri comece uma superação de sua leitura

\footnotetext{
10“ $\mathrm{O}$ clima intelectual francês lhe era familiar desde muito cedo, posto que passou o ano acadêmico de 1954-55 na École Normale na 'rue d'Ulm', e nesse período acompanhou os cursos de Hyppolite, Alquié, Bachelard e Gurvitch. No ano anterior, como um responsável jovem membro da Ação Católica em Pádua, ele havia escolhido passar um ano em um kibutz do Mapam em Israel, e lá tornou-se um comunista. Em meados da década de 50, dessa forma, ele era um comunista - mas um que não havia se tornado pela via marxista e não era conectado ao Partido Comunista Italiano; ele cresceu na cultura francesa e, além disso, era um grande leitor de Merleau-Ponty, que havia acabado de romper com Sartre e estava intentando elaborar uma filosofia política que parece, em muitos aspetos, antecipar a crítica do marxismo italiano em que Negri terá um papel uma década depois" (REVEL, 2007, p. 103).
} 
lukacsiana desta, abrindo caminho para sua conexão com o pós-estruturalismo ${ }^{11}$ (MURPHY, 2011, p. 53-5); (2) em 1978 Negri apresentou na ENS, a convite de Althusser, um seminário dedicado aos Grundrisse, de Marx, que viriam a constituir o livro Marx além de Marx (2016).

Com efeito, é justamente nesse curso que Negri declara a sua posição perante o antihumanismo althusseriano: segundo o italiano, o humanismo e suas noções sobre essência humana e sua restituição através da transição ao comunismo devem ser abandonadas “Althusser não está errado em considerar como signo decisivo de 'bom marxismo' o traçado de limites claros que expulsem essa baboseira insípida da teoria" (NEGRI, 2016, p. 268). Negri aceita, assim, o primeiro momento da crítica anti-humanista, a da desconstrução da metafísica do sujeito e da ideia de Homem. O desenvolvimento da luta de classes e a construção do comunismo "é luta, ruptura, criação. Em nenhum caso, restauração de uma essência originária. Aqui o humanismo não participa em absoluto" (NEGRI, 2016, p. 79). Entretanto, diferentemente de Althusser, Negri não bloqueia a pesquisa em torno da subjetividade determinada historicamente. Pelo contrário:

Ao evitar o humanismo, alguns poderiam também buscar evitar os campos teóricos da subjetividade ${ }^{12}$. A via da subjetividade, no entanto, é a que confere materialidade ao comunismo. A classe operária é subjetividade, subjetividade cindida, que anima o desenvolvimento, a crise, a transição e o comunismo. (NEGRI, 2016, p. 268).

Como veremos, isso se dá por uma leitura diferente da de Althusser da obra marxiana e por concepções diferentes no que concerne à subjetividade.

Contrariamente ao movimento final do anti-humanismo althusseriano, que se fecha em uma postura de antissubjetividade, Etiénne Balibar (2003), antigo aluno e colaborador de Althusser e um dos principais continuadores de sua obra, mantendo-se fiel ao marxismo, faz uma reconstrução diferente do movimento de pensamento efetuado no (pós-)estruturalismo. Balibar afirma que o estruturalismo em geral não foi uma destituição do sujeito ou da subjetividade em todas as suas acepções. Não haveria um momento estruturalista do

\footnotetext{
${ }^{11}$ Ver, sobre o latente avanço de Hyppolite sobre os problemas que caracterizariam o estruturalismo, o texto de Deleuze intitulado Jean Hyppolite, lógica e existência (DELEUZE, 2006).

${ }^{12}$ É evidente que a crítica se refere a Althusser e o marxismo estruturalista que o rodeia. Ainda assim, é importante notar que para o filósofo italiano Althusser constitui uma figura de grande importância para o marxismo. Embora Negri saliente a clara divergência entre seus pontos de vista e os do Althusser "clássico", que teria ficado evidente no momento do curso de Marx além de Marx, afirma uma grande aproximação, inclusive pessoal, nos anos 80, quando da empreitada, por parte de Althusser, do materialismo do encontro ou materialismo aleatório. "Althusser permanece uma figura chave. Ele é fundamental na elaboração do marxismo para o século XXI." (NEGRI, 2005, p. 159). Sobre o materialismo do encontro ver: Althusser (2005), Negri, (2013). Irene Viparelli (2012) e Day (2011) intentam, respectivamente, uma complementaridade e uma aproximação entre o último Althusser e a ontologia constituinte de Negri.
} 
pensamento francês, em que as estruturas tomaram conta de todas as possibilidades do pensamento e proibiram um pensamento da subjetividade - para então, após Maio de 68, emergir o "pós-estruturalismo" enquanto um movimento de rejeição da estrutura e da sistematicidade com a finalidade de reabilitar a subjetividade. Para o autor, ambos esses objetivos, abarcar a estrutura e o sujeito, o objetivo e o subjetivo, constituem parte do mesmo projeto:

Minha hipótese é precisamente a de que não há, de fato, algo como pósestruturalismo, ou melhor, que o pós-estruturalismo (que recebeu este nome no curso de sua 'exportação' internacional, 'recepção', ou 'tradução, ${ }^{13}$ ) é sempre ainda estruturalismo, e estruturalismo em seu sentido mais forte é já pós-estruturalismo. (BALIBAR, 2003, p. 11).

Balibar não nega, em absoluto, a distinção entre os termos, mas os subverte e os ressignifica. Antes de haver uma ruptura identificada diacronicamente, o pós-estruturalismo como um movimento de reação ao estruturalismo, Balibar defende uma distinção sincrônica entre ambos, como dois aspectos distintos de um mesmo movimento. Esses dois momentos seriam: (1) uma destituição do Sujeito próprio dos diferentes humanismos e uma reconstrução das subjetividades através da análise estrutural (nos diferentes campos de pesquisa) momento estruturalista; (2) uma crítica da norma e da normatividade, um reconhecimento da fragilidade e da maleabilidade das estruturas e do potencial de metamorfose encontrado na subjetividade, visto que o duplo sentido, já evocado, da noção de sujeito, através da fórmula "não há sujeito sem subjetificação [no subject without subjetification]” (BALIBAR, 2003, p. 17, grifo do autor), é entendida em seu paradoxo de forma radical. O sujeito é simultaneamente passivo e ativo, assujeitamento e subjetificação - é o aceitar dessa condição paradoxal do sujeito que abre caminho para uma resistência, interna à estrutura e ao processo de subjetificação/assujeitamento. Esse é o momento pós-estruturalista (BALIBAR, 2003).

Como pretendemos mostrar, a obra de Negri está muito próxima desses movimentos afirmados por Balibar. Não pretendemos, porém, afirmar que Negri é um (pós-)estruturalista. Sua obra é bastante original e possui, desde os anos 60, uma marca definitória do contexto político e teórico italiano e uma preocupação com o marxismo não tão explícita nos

\footnotetext{
${ }^{13}$ Balibar se refere, ao que tudo indica, à recepção do pensamento estruturalista nos Estados Unidos, sobretudo através da obra de Foucault e Derrida. Sobre esse assunto, ver o livro de François Cusset intitulado French Theory, cujo foco é, justamente, a recepção das teorias estruturalistas na academia norte-americana. Um de seus subcapítulos é intitulado, sugestivamente, "A invenção do pós-estruturalismo (1966)". A tradução para o português dessa obra possui o título enganador de Filosofia Francesa (2008), escondendo assim o tom próprio da obra.
} 
pensadores estruturalistas. Afirmamos, entretanto, acompanhando Timothy Murphy (2011), que sua obra aceita problemas análogos e premissas parecidas com as do (pós-)estruturalismo, próprias, diríamos, de um pensamento diretamente preocupado com a constituição de um pensamento materialista contemporâneo. Concordamos, porém, com Balibar (2003, p. 2) quando ele afirma, sobre o (pós-)estruturalismo, que "o movimento estruturalista, múltiplo e incompleto por sua própria natureza, ainda está acontecendo - embora possa estar em lugares e sob denominações que nós não consigamos reconhecê-lo imediatamente". A obra de Negri é, imaginamos, um dos locais em que algo desse movimento persiste.

Pois bem, voltemos ao desenvolvimento marxista e à crítica de Negri a Althusser. Diferentemente do francês, Negri não proíbe a pesquisa no sentido da subjetividade e de seu potencial revolucionário. A sua concepção de ciência marxista, longe de ser um corte em relação à ideologia/subjetividade, como no modelo althusseriano, passa, justamente, pela subjetividade $^{14}$. A ciência marxista, para Negri, em um movimento que vai ao encontro do operaísmo italiano e de sua copesquisa dentre os movimentos e os trabalhadores (CAVA, 2012), não pode ser hipostasiada acima do próprio movimento de luta, do antagonismo que se constitui em subjetividade de classe. Por exemplo, para Negri, com a construção da teoria do mais-valor e a descoberta da exploração, esta se converte na "rótula, na síntese dinâmica do pensamento de Marx, no ponto ao redor do que se articulam a análise objetiva do capital e a subjetiva do comportamento de classe, a partir do que o ódio de classe transmite à ciência" (NEGRI, 2016, p. 41). Não há separação, para Negri, entre ciência marxista e subjetividade. A sua leitura do "corte epistemológico" na obra de Marx diverge radicalmente da de Althusser: “O corte epistemológico é o nascimento da organização, o que torna o ponto de vista científico sobre a realidade existente em um conjunto de ferramentas técnicas para um processo de desconstrução do estado presente das coisas" (NEGRI, 2005, p. 54). Mas ele esclarece em nota:

No pensamento de Marx a passagem da juventude para a maturidade certamente representa uma transformação do seu horizonte teórico (e os momentos desta transformação são mais ou menos aqueles que Althusser indica). Entretanto, essa passagem não é um salto. O materialismo histórico e a demanda dialética por organização levam em consideração, na verdade eles estudam em profundidade, o

\footnotetext{
${ }^{14}$ A ideologia não constitui um conceito fundamental do léxico de Negri (e Michael Hardt, seu coautor recorrente). Sua concepção de subjetividade não passa pela ideologia, o que o coloca mais próximo de outros (pós-)estruturalistas, como Foucault e Deleuze, do que de Althusser. Como os autores colocam em Bem-Estar Comum (2016, cap. 2.1), o conceito de ideologia não é suficiente para entender o contemporâneo, sendo necessária uma transição para o conceito de biopolítica. Não pretendemos, porém, uma discussão sobre esse ponto.
} 
significado e a importância do histórico sujeito 'proletário' [of the historical 'proletarian' subject]. Longe de acabar em um 'processo sem sujeito', a evolução do pensamento de Marx acompanha de perto a realidade organizacional do sujeito revolucionário. O verdadeiro resultado da crítica da economia política é sempre necessariamente essa ancoragem subjetiva. ${ }^{15}$ (NEGRI, 2005, p. 114, n. 6).

Enquanto para Althusser o corte epistemológico separa o humanismo e a metafísica do Sujeito do marxismo propriamente científico, que analisa esquematicamente e logicamente (como em $O$ Capital) as contradições do modo de produção, Negri afirma que o "corte" se dá entre o mesmo humanismo do Sujeito e uma análise material, através da crítica da economia política, das subjetividades revolucionárias; da metafísica do Sujeito às subjetividades constituídas historicamente e cindidas em um movimento de luta insurrecional.

\section{MÉTODO OPERAÍSTA E SUBJETIVIDADE}

O operaísmo italiano, nascido na década de 60, construiu um marxismo bastante singular. Em geral trabalhando de fora do Partido Comunista Italiano (PCI), distantes de suas sucessivas guinadas teoricamente humanistas e praticamente social-democratas. Filosoficamente, uma das características mais anômalas do marxismo operaísta é sua distância do conceito ou do método dialético. O operaísmo ia mais além do que o maoísmo ou do que Althusser (inspirado pelo maoísmo), visto que estes rejeitavam a dialética hegeliana, rejeitando a Aufhebung ou a "negação da negação" em prol da construção de uma dialética propriamente marxista - o que Althusser chama de materialismo dialético ${ }^{16}$. O operaísmo não rejeitava apenas a dialética hegeliana aplicada ao marxismo, mas qualquer inspiração dialética.

Ponto fundamental dessa rejeição, e dos posteriores desenvolvimentos de Negri, é a chamada "hipótese operaísta", lançada por Mário Tronti em 1964 em texto intitulado Lenin na Inglaterra e publicado na primeira edição da revista Classe Operaia. Tronti (1976, p. 93) colocava:

Também nós próprios começamos por ver primeiro o desenvolvimento capitalista e só depois as lutas operárias. É um erro. Tem de se inverter o problema, muda-lo de sinal, recomeçar desde o princípio: e o princípio é a luta de classe operária. Ao nível do capital socialmente desenvolvido, o desenvolvimento capitalista é subordinado às

\footnotetext{
${ }^{15}$ Devemos a percepção da importância deste trecho a Timothy Murphy (2011).

${ }^{16}$ Sobre a relação Althusser-Mao e a crítica da negação da negação, ver Motta (2014, cap. 2).
} 
lutas operárias, vem depois delas e a elas tem de fazer corresponder o mecanismo político da sua própria produção.

O trecho em questão exprime bem a proposta operaísta. Antes de pensar um marxismo cientificista e economicista, intentava-se pensar a partir das lutas, do ponto de vista das lutas, dos operários. A "hipótese" de Tronti foi seguida por Negri com entusiasmo.

O marxismo que Negri encontra e desenvolve é marcado pelo contexto operaísta intensamente, tanto teórica quanto politicamente. Como ele coloca, "os anos 60 já haviam sido caracterizados por uma releitura de Marx, aquela de Mario Tronti - uma releitura enormemente inovadora, em minha opinião" (NEGRI, 2005, p. 156). Outro ponto que marca profundamente o método marxista/marxiano utilizado por Negri é a publicação italiana dos Grundrisse, de Marx, entre 1968 e 1970 (TRONTI, 2008, p. 229). Os Grundrisse, publicados pela primeira vez apenas em 1941 em Moscou, são os cadernos de Marx escritos entre 1857 e 1858 em que o autor efetuava suas pesquisas sobre metodologia e economia política, marcados pela efervescência de uma crise econômica e por uma abertura política revolucionária que transparece no texto. As primeiras aparições de alguns conceitos-chave de O capital, de 1867, se encontram nesses cadernos. O operaísmo, que já vinha afirmando a centralidade da classe operária em luta, antes que das sistematizações categóricas sobre os movimentos da economia política e os desenvolvimentos do capitalismo, encontrou nos Grundrisse e em sua abertura para a luta e para potência da crise uma forte base teórica: "os Grundrisse eram importantes por acentuarem as características metodológicas (portanto subjetivas, epistemológicas) do discurso marxista que desenvolvemos no operaísmo dos anos 60 em diante" (NEGRI, 2005, p. 156-157).

Podemos marcar diferença entre os marxismos da época tomando em conta os textos marxianos que tomavam como base principal: o marxismo próprio das linhas stalinistas dos Partidos Comunistas oficiais vinculados à URSS pretendia uma ciência do materialismo histórico, flertando com o determinismo histórico e com o economicismo, através do Manifesto comunista e de $O$ capital; O marxismo humanista tomava no "Jovem Marx" e nos Manuscritos econômico-filosóficos, com as noções feuerbachianas de essência do Homem e de alienação do trabalho, sua principal chave de leitura; o operaísmo tomou nos Grundrisse e nas suas pesquisas em torno da subjetividade em luta e cindida, do antagonismo social e da 
socialização radical da produção (em um grau ausente de outras obras de Marx), sua principal base teórica e metodológica. ${ }^{17}$

Segundo Negri, "Nos Grundrisse, o marxismo é uma teoria antieconômica” (2016, p. 44, grifo do autor). A necessidade de conceber um marxismo que saiba lidar com as lutas emergentes nos anos 60 e 70, sobretudo após 68, exige um antieconomicismo que as linhas estalinistas da Terceira Internacional não podiam dar. Entretanto, exige simultaneamente um marxismo que saiba lidar com as lutas e analisá-las de forma materialista, sem diluí-las em princípios idealistas ou humanistas - é necessário entender as lutas em sua materialidade e em suas determinações, sem por isso reduzi-las ao objetivismo do desenvolvimento do capital. Os Grundrisse se tornam a base desse projeto. É necessário saber separar o que é do capital e o que é do proletariado; deve-se tomar o cuidado de não diluir a subjetividade da classe que luta no Sujeito total e totalizante que é o capital: "é preciso que essa estrutura, essa totalidade, sofra uma fratura de seu interior. É preciso que cheguemos ao ponto de captar não somente a subjetividade estrutural (capitalista), mas também as subjetividades que dialeticamente constituem a estrutura (as duas classes em luta)" (NEGRI, 2016, p. 98). Os Grundrisse constituem, assim, uma base teórica mais potente na construção, prática e teórica, da hipótese operaísta. $O$ capital utiliza um "método mais idealista, mais hegeliano, apesar das intenções e declarações em contrário" (NEGRI, 2016, p. 89). Em O capital, Marx faz uma análise do desenvolvimento capitalista "do ponto de vista do capital", uma análise dialética, na qual a subjetividade proletária, quando aparece, é submetida ao desenvolvimento da contradição, é reduzida a um momento do capital, ao invés de ser pensada enquanto força antagonista contra o capital, contra a exploração e a lei do mais-valor. Dessa forma, é um livro dialético: “ $O$ Capital é, ao mesmo tempo, o texto que serviu para reduzir a crítica à teoria econômica, neutralizar a subjetividade na objetividade, e o proletariado subversivo, na reestruturação de sua repressão e dominação" (NEGRI, 2016, p. 58).

O objetivo marxista e materialista sublinhado anteriormente, de pesquisar nos contextos específicos geográfica, econômica e historicamente as diferentes formas de subjetividade e de luta passa pela noção operaísta de composição de classe. Uma classe social, segundo os operaístas, é fruto de uma complexa composição de diferentes elementos materiais, estruturais, objetivos e subjetivos. Ela se divide em duas partes: composição

\footnotetext{
${ }^{17} \mathrm{Na}$ construção deste parágrafo nos baseamos na vinculação das obras de Marx aos diferentes marxismos apresentada por Weeks (2005).
} 
técnica, que poderíamos chamar de aspecto estrutural; e composição política, que poderíamos chamar de aspecto subjetivo. Como resume Matteo Mandarini (2010, p. 19),

\begin{abstract}
a noção de composição de classe reúne dois aspectos: um aspecto técnico, que envolve uma análise do mundo da produção, sua transformação, e os efeitos sobre o sujeito do trabalho, incluindo o desenvolvimento de um certo nível de necessidades e desejos. O segundo aspecto, a composição política, refere-se às formas que este primeiro - pelo menos parcialmente determinado tecnologicamente - pode ser apropriado politicamente.
\end{abstract}

É importante salientar, porém, que os dois aspectos da composição de classe são ontologicamente simultâneos: não há distinção real entre ambos, apenas formal; ou, também poderíamos dizer, distinguir composição técnica de classe e composição política de classe é uma operação analítica. Os dois aspectos da composição de classe se dão simultaneamente, não há prevalência de um sobre o outro, nem mesmo em um nível formal: "A dupla abordagem era apenas metódica. Na verdade, a definição era absolutamente compacta e as articulações eram verificadas justamente na dimensão do vivido" (NEGRI, 2017, p. 160).

Perpassa pela obra de Negri uma constante preocupação em pensar as diferentes composições de classe desde o início do século XX - dessa forma, através da análise dos processos de trabalho e dos diferentes contextos políticos pode-se afirmar a existência do operário profissional, na Rússia de Lenin antes de Outubro: operários tecnicamente sofisticados que eram necessários para supervisionar e coordenar os operários "leigos" e que, justamente por isso, poderiam fazer uma fábrica parar quando quisessem. Na verdade, o operário profissional existia em formas bastante similares em outros países de capitalismo relativamente desenvolvido, porém o foco de Negri é na questão russa exatamente porque é ali que houve uma forte assimilação política da composição técnica. Em uma espécie de analogia, é justamente porque os trabalhadores "leigos" possuem os trabalhadores "profissionais" como seus supervisores em seu meio produtivo, na fábrica, que, politicamente, se instaura uma relação de dependência entre as massas trabalhadoras e a vanguarda revolucionária do Partido. Acompanhando a hipótese operaísta (as lutas operárias vêm primeiro, o desenvolvimento capitalista vem depois), Negri afirma que o Capital intentou, dentre 1917 (o ano da Revolução Russa) e 1929 (o ano da crise), um ataque à prévia composição de classe (a do operário profissional) a fim de extinguir as condições técnicas e políticas que possibilitaram a revolução bolchevique. Dessa forma, passa-se ao operáriomassa, como o tradicional operário do fordismo e do Estado de bem-estar e keynesiano, 
agregado ao capitalismo e tornado tecnicamente homogêneo, visto que a operabilidade das máquinas introduzidas pouco exigia em qualificação. A principal forma de organização política da classe, à época, são as organizações de massa nas modalidades do Partido (não o de vanguarda) e dos sindicatos. Finalmente, na pesquisa que marcou a tradição operaísta nos anos 70, Negri assinala a transição para o chamado operário social (MURPHY, 2011, p. 7177). Basicamente, enquanto o operário-massa, industrial, possuía grande homogeneidade e trabalhava em um regime disciplinar claro, com a fábrica concentrando todo o tempo de trabalho necessário e mais-trabalho, o operário social é caracterizado por uma grande socialização do trabalho, na qual o chão de fábrica perde centralidade pois a própria sociedade se transforma em local de produção, "fábrica social" ". Murphy afirma que a hipótese do operário social teve resistências inclusive dentre teóricos operaístas, mas teve algumas de suas verificações empíricas através de uma "contínua educação para apoiar a flexibilização do emprego, serviços sociais para apoiar a mobilidade do trabalho e Estado de bem-estar para apoiar longos períodos de desemprego, por exemplo" (2011, p. 77). O operário social, por fim, constitui-se em uma forma de autonomização em relação ao capital, visto que ele depende mais das redes de trabalho espalhadas socialmente do que dos meios de trabalho colocados pelo próprio capital no local de trabalho industrial, na fábrica.

Essa complexa imbricação de teoria e de análise das metamorfoses do desenvolvimento capitalista acaba por fundamentar a virada antidialética do marxismo operaísta. Os Grundrisse, como vimos, constituem obra fundamental para a perspectiva marxista intentada por Negri exatamente porque estão presentes, nele, simultaneamente um horizonte de crise (causado pela crise monetária de 1857) e uma abertura para o antagonismo e para a subjetividade dos trabalhadores em luta. Assumindo o ponto de vista da classe, do antagonismo antes que da dialética e da contradição (visto que a contradição é interna à totalidade do capital e apenas o meio de seu movimento), Marx apresenta capital e trabalho enquanto coisas opostas e diferentes: "A única coisa distinta do trabalho objetivado [quantificado pelo capital] é o trabalho não objetivado, mas ainda se objetivando, o trabalho como subjetividade." (MARX, 2011, p. 212, grifo nosso). Marx assume, dessa forma, uma perspectiva subjetivista, que se fará ausente quando da escrita de $O$ capital e de suas contradições e sínteses, de sua dialética. A partir da crise do controle capitalista encadeada pela socialização da produção nos anos 70 o ponto de vista da classe se abre com maior

\footnotetext{
${ }^{18}$ Embora Negri a tenha assumido também, Murphy $(2011$, p. 77$)$ salienta que a expressão "fábrica social" foi cunhada por Tronti.
} 
intensidade para além da totalização da dialética do capital, colocando classe e capital em confronto imediato: "valor de troca contra valor de uso [;] trabalho objetivado contra trabalho subjetivo" (NEGRI, 2016, p. 134, grifo do autor). "A diferença entre os Grundrisse e as obras posteriores de Marx está no fato de que, nos Grundrisse, a lei do valor se apresenta não como uma mediação, mas imediatamente como lei da exploração" (NEGRI, 2016, p. 65, grifo do autor). O mesmo ocorre no contexto da "fábrica social".

Como expõe Cocco (2015, p. 344), "não há teoria do comunismo que não seja uma teoria da formação do sujeito ao mesmo tempo que a circulação do capital é seu devir e esse devir é mesmo o movimento de socialização do capital, de construção de uma sociedadefábrica”. Esta formação do sujeito foi descoberta por Negri, no contexto operaísta e em diante, como o caminho para "reafirmar o comunismo. [...] como enfrentamento presente contra a ordem das coisas; contra a exploração e a autovalorização do capital, o comunismo como autovalorização operária e descoberta de uma subjetividade revolucionária em ação" (SANTIAGO; VERSOLATO, 2016, p. 11). O comunismo é uma ação imanente e atual, não um estado de coisas lançado ao futuro. É nesse sentido que a via da subjetividade leva ao comunismo - Repetindo: “A via da subjetividade, no entanto, é a que confere materialidade ao comunismo. A classe operária é subjetividade, subjetividade cindida, que anima o desenvolvimento, a crise, a transição e o comunismo." (NEGRI, 2016, p. 268).

\section{CONSIDERAÇÕES FINAIS}

Vimos como Negri acompanha a necessidade de abandonar qualquer noção metafísica do Humano e da humanidade, as noções modernas que flertam com um sujeito trans-histórico em sua interioridade e essência, seja ela o trabalho, o cogito, etc. Ao contrário do marxismo humanista, também, o objetivo da libertação (do comunismo) não é a restauração jogada ao futuro de alguma essência alienada no presente. Ao mesmo tempo, porém, o autor defende que o campo da subjetividade, negado pelo anti-humanismo althusseriano como ponto de articulação revolucionário, é por onde deve passar a pesquisa marxista. A pesquisa operaísta sobre as transformações na composição de classe é um dos principais pontos de apoio para a identificação dessa subjetividade anti-humanista, dessa subjetividade que se desvencilha das noções de Sujeito moderno, criticadas pelo antihumanismo (MURPHY, 2011, p. 71). 
Mostramos, finalmente, que a importância dada por Negri à subjetividade na pesquisa marxista está longe das concepções humanistas nas formas criticadas por Althusser. A subjetividade é descoberta importante como momento da luta e do desenvolvimento através de materiais e históricas pesquisas sobre a composição de classe, o que leva à perspectiva de uma cisão na totalidade posta pela relação do capital. Althusser, limitado por uma concepção de ideologia totalizante, se impossibilitava de perceber, justamente, essa cisão. Negri, através da pesquisa sobre a composição de classe, acompanhando o duplo movimento que nomeamos de (pós-)estruturalismo, pervertendo as palavras de Balibar (2003) (mas não seu sentido), efetua até o final a pesquisa iniciada por Althusser: a destituição da metafísica do Sujeito e a reconstrução histórica e aberta das subjetividades ("momento estruturalista"); e a abertura da totalidade estrutural para a sua multiplicidade formacional, a sua cisão através da subjetividade e da resistência ("momento pós-estruturalista"). Althusser, parece, não pode efetuar radicalmente a segunda parte do movimento. Negri avança de um modo materialista a necessidade de se pensar a subjetividade enquanto cisão revolucionária ao mesmo tempo em que enfrenta os aspectos estruturais das transformações da economia e das formas de trabalho capitalistas, sempre reabrindo a pesquisa aos novos ciclos de luta.

\section{REFERÊNCIAS}

ALTHUSSER, Louis. Posições 1. Rio de Janeiro: Graal, 1978.

ALTHUSSER, Louis. Aparelhos ideológicos de estado. Rio de Janeiro: Graal, 1983.

ALTHUSSER, Louis. Por Marx. Campinas: Editora Unicamp, 2015.

ALTHUSSER, Louis. A querela do humanismo. Crítica Marxista, São Paulo, Xamã, nº 9, 1999.

ALTHUSSER, Louis. A querela do humanismo II. Crítica Marxista, São Paulo: Boitempo, v. 1, n. 14, 2002, p. 48-72.

ALTHUSSER, Louis. A corrente subterrânea do materialismo do encontro. Crítica Marxista, 20, p. 9-48. Rio de Janeiro, Ed. Revan, 2005.

ALTHUSSER, Louis. A propósito do artigo de Michel Verret sobre o 'Maio estudantil'. Crítica Marxista, São Paulo, n. 44, 2017, p. 23-135.

ALTHUSSER, Louis et al. Ler O capital. Rio de Janeiro: Zahar, 1980. 
ALTHUSSER, Louis; NAVARRO, Fernanda. Filosofía y marxismo. México: Siglo XXI, 1988.

BALIBAR, Étienne, Structuralism: A destitution of the subject? Differences, 14 (1), 2003, p. $1-21$.

CAVA, Bruno. A copesquisa militante no autonomismo operaísta. Lugar Comum, Rio de Janeiro: UFRJ, n. 37-38, maio-dez. 2012a, p. 17 - 38.

COCCO, Giuseppe. Posfácio - Negri além de Negri (2015). In: NEGRI, Antonio. Marx além de Marx: Ciência da crise e da subversão - Cadernos de trabalho sobre os Grundrisse.

Tradução de Bruno Cava. São Paulo: Autonomia Literária, 2016, p. 323-349.

CUSSET, François. Filosofia francesa: a influência de Foucault, Derrida, Deleuze \& Cia. Tradução de Fátima Murad. Porto Alegre: Artmed, 2008.

DAY, R. E. The Aleatory Encounter and the Common Name: Reading Negri Reading Althusser. Journal of Communication Inquiry, v. 35, nº 4, 2011, p. 362-369.

DELEUZE, Gilles. Jean Hyppolite, Lógica e Existência. In: DELEUZE, Gilles. A Ilha deserta e outros textos. São Paulo, Iluminuras, 2006, p. 18-23.

GUATTARI, Félix; NEGRI, Antonio. As verdades nômades: por novos espaços de liberdade. São Paulo: Autonomia Literária e Editora Politeia, 2017.

HALLWARD, Peter. Introduction: Theoretical Training. In: HALLWARD, Peter; PEDEN, Knox (ed.). Concept and Form - v. 1 - Key Texts from the Cahiers pour l'Analyse.

London/New York: Verso, 2012, p. 1-55.

HARDT, Michael; NEGRI, Antonio. Bem-estar comum. Tradução de Clóvis Marques. Rio de Janeiro: Record, 2016.

MANDARINI, Matteo. Organizing Communism. In: GUATTARI, Félix; NEGRI, Antonio. New lines of alliance, new spaces of liberty. New York: Autonomedia, 2010.

MANIGLIER, Patrice, The Structuralist Legacy. In: SCHRIFT A. (ed.). The History of Continental Philosophy, v. 7: "After poststructuralism: transformations and transitions" (Rosi Braidotti, ed.). London: Acumen Press, 2010, p. 55-82.

MARX, Karl. Crítica da filosofia do direito de Hegel. Tradução de Rubens Enderle e Leonardo de Deus. São Paulo: Boitempo, 2010a.

MARX, Karl. Manuscritos econômico-fillosóficos. São Paulo, Boitempo, 2010b.

MARX, Karl. Grundrisse: manuscritos econômicos de 1857-1858: esboços da crítica da economia política. Tradução de Mario de Duayer e Nélio Schneider. São Paulo: Boitempo, 2011.

MARX, Karl. O capital. Crítica da economia política: Livro I - O processo de produção do 
capital. Tradução de Rubens Enderle. São Paulo: Boitempo, 2015.

MARX, Karl; ENGELS, Friedrich. A ideologia alemã. São Paulo: Boitempo, 2007.

MONTAG, Warren. Louis Althusser. In: SCHRIFT, A. D. (ed.). Post structuralism and critical theory's second generation, vol. 6 of SCHRIFT, A. D. (ed.). The history of continental philosophy (8 vols.), University of Chicago Press, 2010, p. 47-65.

MOTTA, Luiz Eduardo. A favor de Althusser: revolução e ruptura na teoria marxista. Rio de Janeiro: Grama; FAPERJ, 2014.

MURPHY, Timothy S. Antonio Negri: modernity and the multitude. Cambridge: Polity, 2011.

NEGRI, Antonio. A anomalia selvagem: poder e potência em Spinoza. Tradução de Raquel Ramalhete. Rio de Janeiro: Ed. 34, 1993.

NEGRI, Antonio. Cinco lições sobre império. Tradução de Alba Olmi. Rio de Janeiro: DP\&A, 2003.

NEGRI, Antonio. From sociological to ontological inquiry: An Interview with Antonio Negri (by Max Henninger). Italian Culture, vol. 23 no. 1, 2005, pp. 153-166.

NEGRI, Antonio. De volta: abecedário biopolítico. Rio de Janeiro: Record, 2006.

NEGRI, Antonio. Jó: a força do escravo. Tradução de Eliana Aguiar. Rio de Janeiro: Record, 2007.

NEGRI, Antonio. A favor de Althusser. Notas sobre a evolução do pensamento do último Althusser. Tradução de Pedro Eduardo Zini Davoglio. Lugar Comum, n. 41, set.-dez. 2013, p. 51-69.

NEGRI, Antonio. Marx além de Marx: ciência da crise e da subversão - Cadernos de trabalho sobre os Grundrisse. Tradução de Bruno Cava. São Paulo: Autonomia Literária, 2016.

NEGRI, Antonio. Carta Arqueológica. In: GUATTARI, Félix; NEGRI, Antonio. As verdades nômades: por novos espaços de liberdade. São Paulo: Autonomia Literária e Editora Politeia, 2017, p. 149-169.

REVEL, Judith. Antonio Negri, French Nietzschean? From the will to power to the ontology of power. In: MURPHY, T. S.; MUSTAPHA, A. K. (ed.). The philosophy of Antonio Negri - Vol. Two: Revolution in Theory. London: Pluto Press, 2007, p. 87-108.

RICOEUR, Paul. Althusser's theory of ideology, In: ELLIOTT Gregory (ed.). Althusser: a critical reader. Blackwell, 1994, p. 44-72.

ROCHA, Acílio. E. Dialética e ideologia em Althusser, Revista Portuguesa de Filosofia, tomo XXXII n. 3-4, 1976, p. $305-324$. 
SANTIAGO, Homero; VERSOLATO, Rafael. Prefácio - Ciência da Crise e da Subversão. In: NEGRI, Antonio. Marx além de Marx: Ciência da crise e da subversão - Cadernos de trabalho sobre os Grundrisse. Tradução de Bruno Cava. São Paulo: Autonomia Literária, 2016, p. 9-23.

THOMPSON, Edward Palmer. A miséria da teoria. Rio de janeiro: Zahar Editores, 1981.

TRONTI, Mario. Operários e Capital. Porto: Edições Afrontamento, 1976.

TRONTI, Mario. Italy. In: Marcello Musto (ed.), Karl Marx's Grundrisse - Foundations of the critique of political economy 150 years later, New York: 2008, p. 229-235.

VIPARELLI, Irene. Althusser e Negri: Uma complementaridade aporética?. Princípios Revista de Filosofia, Natal, v. 19, n. 32, jul.-dez. de 2012, p. 273-300.

WEEKS, Kathi. The refusal of work as demand and perspective. In: MURPHY, T. S.; MUSTAPHA, A. K. (ed.). Resistance in practice: the philosophy of Antonio Negri. London: Pluto Press, 2005, p. 109-135. 